\title{
Seguindo AS PIPAS COM A METOdologia dA TAR
}

\author{
Maria de Fátima Aranha de Queiroz e Melo
}

\begin{abstract}
RESUMO
À luz das idéias de Bruno Latour, buscamos elaborar os rudimentos para uma psicologia social do brinquedo, tomando a Teoria Ator-Rede como metodologia para registrar tal construção. Elegemos a pipa, objeto de tradição milenar que encerra múltiplas histórias, como objeto a ser investigado nas redes que garantem a sua sobrevivência, nas aprendizagens que suscita, nos efeitos que promove. Discutiremos os princípios e regras metodológicas da Teoria Ator-Rede, testando a sua aplicabilidade ao nosso objeto de pesquisa, tentando, sempre que possivel, fertilizar uma reflexão para o campo de estudo da psicologia, que é onde se situa o seguimento de nossa ação.
\end{abstract}

Palavras-chave: Psicologia Social. Brinquedo. Teoria Ator-Rede.

\section{Following KITES WITH ANT METHODOLOGY}

\begin{abstract}
Taking Bruno Latour's ideas into account, we have tried to elaborate the underlying principles of a toy social psychology, taking the Actor-Network Theory as methodology to register this construction. We have selected the kite, millenary traditional object which carries multiple stories, in the networks which guarantee its survival, in the learning it suscitates, in the effects that it promotes. We will discuss the principles and the methodological rules of the Action-Network Theory, testing its applicability to our research object, trying, whenever it is possible, to enrich a reflection towards the psychology field of studies in which our action takes place.
\end{abstract}

Keywords: Social Psychology. Toy. Actor-Network Theory.

\footnotetext{
* Psicóloga, professora do Departamento das Psicologias da Universidade Federal de São João del Rei e membro do LAPIP (Laboratório de Pesquisa e Intervenção Psicossocial), mestre em Educação pela PUC-Rio, doutoranda no Programa de Pós-Graduação em Psicologia Social da UERJ, sob a orientação do Profofesor Doutor. Ronald João Jacques Arendt. Fonte de financiamento: bolsa de doutorado Capes PQI, UFSJ/UERJ. Endereço: Rua Luis Carlos do Nascimento, 364. Residencial São Caetano. São João del Rei - MG, CEP: 36.309.118.

E-mail: queirozmaldos@uaivip.com.br
} 


\section{SEguindo AS PIPAS COM A METOdOLOGIA DA TAR}

A Teoria Ator-Rede (TAR) nasceu no interior de um campo chamado Estudos da Ciência e Tecnologia e vem sendo trabalhada desde os anos 1980 para atender ao Princípio de Simetria instaurado pela Antropologia das Ciências, disciplina transversal que surgiu influenciada pela convergência dos estudos em diversos campos do conhecimento. Em linhas gerais, a Teoria Ator-Rede defende a idéia de que, se os seres humanos estabelecem uma rede social, não é apenas porque eles interagem com outros seres humanos, mas é porque interagem com seres humanos e com outros materiais também. A TAR permite verificarmos uma multiplicidade de materiais heterogêneos conectados em forma de uma rede que tem múltiplas entradas, está sempre em movimento e aberta a novos elementos que podem se associar de forma inédita e inesperada. Todos os fenômenos são efeitos dessas redes que mesclam simetricamente pessoas e objetos, dados da natureza e dados da sociedade, oferecendo-lhes igual tratamento.

A Teoria Ator-Rede foi concebida, segundo Latour (1996), pela fusão de três eixos de preocupação que legitimam uma prática de estudo integrada: 1) a definição das entidades que atuam nas redes, constituídas de material heterogêneo, destacando a simetria entre os elementos humanos e não humanos; 2) a definição das próprias redes, em sua dinâmica particular, pelas cadeias de tradução e, finalmente; 3) por um quadro metodológico para registrar tal construção. Iremos, neste artigo, nos dedicar à discussão deste quadro metodológico compatível com a TAR para dar conta da tarefa de seguir a pipa em ação e verificar os efeitos por ela produzidos.

Cientes de que as opções epistemológicas estão subjacentes aos métodos e técnicas, tomamos como marco inicial os princípios e regras metodológicas lançadas por Latour (1985, 1996; LATOUR; WOOLGAR, 1997, 2000, 2003). Nestes textos, o autor aborda mais extensamente a tarefa daqueles que constroem fatos e artefatos, assim como rediscute o papel dos pesquisadores à luz de princípios e regras que buscam ser simétricas para todos aqueles envolvidos nos eventos de fabricação.

Quando escreve "Vida de Laboratório" (1997) em parceria com Steve Woolgar, Latour assume a noção de simetria como base moral de seu trabalho. A busca de explicações simétricas implica a recusa de várias distinções: entre o que emerge do social e o que emerge da técnica; entre fatos e artefatos; entre fatores externos e fatores internos como ponto de partida para o entendimento da gênese de fatos e artefatos; entre senso comum e raciocínio científico. Situando-se numa perspectiva simétrica, o pesquisador é definido como resultante dos conflitos de apropriação ocorridos no contexto do laboratório ou campo de estudo, como ponto de uma vasta e heterogênea rede de elementos.

Para o autor (LATOUR; WOOLGAR, 1997), existe, no debate histórico, a tendência de que os fatos construídos sejam vistos como fatos descobertos, obscurecendo as circunstâncias que permitiram a sua emergência enquanto uma construção. A idéia da criação de fatos enquanto ficções científicas convincentes apli- 
ca-se tanto à atividade dos pesquisadores em laboratório como aos pesquisadores de outros campos. Nestes, em vez do laboratório, o pesquisador tem o texto como lugar de suas experiências, utilizando-o para construir uma descrição, para colocar em cena conceitos e personagens, para invocar fontes e relacionar argumentos. Com estas ações, pretende-se diminuir a desordem do mundo pela proposta de enunciados mais verossímeis que outros dentro de uma determinada controvérsia. Para criar ordem a partir da desordem, o pesquisador começa por penetrar em seu campo de estudo às apalpadelas para, lentamente, do ruído e da confusão, fazer emergir "bolsões de ordem" (LATOUR; WOOLGAR, 1997, p. 290). ${ }^{1}$

A única forma de fazer uma organização emergir da desordem, defende Latour (LATOUR; WOOLGAR, 1997), é conservar um traço por meio de uma inscrição. ${ }^{2}$ Fatos e artefatos, pela ação de cientistas e engenheiros, surgem por meio da produção constante de um foco de organização criado a partir da desordem. Todo o conhecimento produzido na história da ciência seria fruto do trabalho de mobilização e transporte de inscrições, fazendo com que pessoas, acontecimentos e lugares sejam levados aos "centros de acumulação" (CA). ${ }^{3}$ A forma de tornar possível esta operação é a invenção de meios que tornem estes elementos: (a) móveis para que sejam transportados; (b) estáveis para que não se distorçam nem se decomponham; (c) combináveis para que possam ser agregados ou embaralhados como um maço de cartas. ${ }^{4}$

Pesquisar necessariamente coloca-nos numa tomada de posição diante de caixas-pretas, ${ }^{5}$ seja para acompanhar as controvérsias que as encerram, seja para acompanhar as controvérsias que as reabrem. Será tarefa do pesquisador, que aparece como metarregra inegociável, permitir aos não-especialistas o acompanhamento de uma controvérsia, por mais tempo e de forma mais independente, mostrando o máximo possível como os elementos se interligam uns com os outros, como se articulam em redes mais - ou menos - extensas, por meios de ligações mais - ou menos - fortes (LATOUR; WOOLGAR, 2000).

Segundo Latour (LATOUR; WOOLGAR, 1997, p. 36) os princípios são "os fatos empíricos que temos em mãos", gerando decisões quanto à forma de considerá-los. Estas decisões constituem as regras metodológicas tomadas como necessárias para o estudo deste campo que o autor chamou de "ciência, tecnologia e sociedade". Dentro da perspectiva de um conhecimento construído em redes, explicitaremos os princípios e, posteriormente, as regras metodológicas deles decorrentes, tentando sempre fertilizar a discussão no campo de estudo da psicologia que é onde se situa o seguimento de nossa ação.

Princípios (LATOUR; WOOLGAR, 1997, p. 423-424): “Os fatos são construídos coletivamente: passam de mão em mão, se deformam e se traduzem, dificilmente mantendo-se estáveis e inalterados". Nas fabricações realizadas pela ciência e pela tecnologia, não há objeto ou teoria que não passe por várias mãos e se valha de elementos heterogêneos (humanos e não humanos) que trocam propriedades, fazendo-se e refazendo-se incessantemente. A pipa, nosso objeto de estudo, é um objeto que, ao passar de mão em mão, vai se modificando ao mesmo tempo em que produz diferentes efeitos, evidenciando uma história de traduções 
que faz do global e do local meras variações de escala. É esse caráter coletivo das fabricações que the confere legitimidade. Este princípio implica diretamente a primeira regra metodológica.

"Os objetos novos emergem como sobreviventes dos testes de força a que são submetidos e têm os cientistas e engenheiros como seus representantes. São 'construções' cuja existência pode ser posta em dúvida" ${ }^{6}$ O pesquisador é, antes de tudo, um fabricador de fatos: mobiliza partes da realidade para transportá-la, combiná-la e recombiná-la nos centros em que se acumulam as informações. É paradoxal, no nosso caso, afirmar que um objeto de aproximadamente três mil anos possa se constituir em um objeto novo. Entretanto, a pretensão de lançar um foco de luz sobre um objeto, ao mesmo tempo banal e potente na mobilização de conexões tão duráveis, pode vir a torná-lo um objeto novo pelas controvérsias que se instauram ao seu redor. A pipa tem resistido com bravura aos testes de força a que lhe condenam, que lhe atribuem uma condição de obsolescência, ou que the decretam a extinção. Um objeto novo, segundo Latour (LATOUR; WOOLGAR, 1997), freqüentemente emerge como uma formação complexa a partir de articulações inéditas com outras disciplinas, pela importação de objetos já sedimentados que foram novos em algum ponto do tempo e do espaço. Este princípio se desdobra diretamente na segunda regra metodológica.

"Estudar/descrever fatos e máquinas é a mesma coisa que entender a tessitura das redes que lhes dão sustentação em suas associações mais fracas ou mais fortes". Quando estudamos/descrevemos os movimentos da pipa, certamente estamos estudando e descrevendo a tessitura das redes que lhe permitem continuar existindo; estaremos falando da história dos elementos humanos e dos elementos não humanos que estão envolvidos nas várias traduções pelas quais tem passado e vai passando em tempos e espaços diversos: estaremos falando ao mesmo tempo de uma natureza e de uma sociedade que aparecem como uma estabilização dessas redes. Este princípio está ligado à terceira e à quarta regra metodológica.

"Quanto mais esotérico o conteúdo da ciência e da tecnologia, mais elas se expandem externamente". A questão dentro/fora das redes encontra aqui uma possível tradução, pois quando o conteúdo da ciência e tecnologia se supõe esotérico, a salvo de pressões externas, é quando ele faz pressão para vazar pelas bordas da rede. Não há conteúdo científico ou tecnológico que sobreviva enclausurado: para não sucumbir ao esquecimento, sempre transbordará e se expandirá externamente. Obviamente, a pipa está longe de fazer parte de um conhecimento esotérico, pois, na condição de um jogo tradicional e de rua, ela se populariza e se difunde à semelhança de um contágio.

"Os fatos duros não são regra, mas exceção, devendo-se perguntar sempre quem será atacado ou alijado por eles". Quando abrimos as caixas-pretas, quando nos propomos a pesquisar um assunto, estaremos abrindo e/ou reabrindo controvérsias e pondo a dureza dos fatos à prova, uma vez que eles são também uma fabricação. ${ }^{7}$ A diferença é que, tornando-se consensuais, aceitos e produtores de efeitos, esses fatos, que se tornaram pontos de passagem obrigatória, tornam-se fatos mais difíceis e mais caros quanto ao desafio de sua veracidade. A pesquisa é uma oportu- 
nidade de testar os fatos duros, de promover um movimento para dissolver preconceitos, para abrir e acompanhar controvérsias, para produzir novas inscrições que possam ser confrontadas com as já existentes, para eventualmente criar objetos novos. Este princípio tem implicação direta nas regras metodológicas 5 e 6 .

"A história da tecnociência é, em grande parte, a história dos recursos espalhados ao longo das redes para acelerar a mobilidade, a fidedignidade, a combinação e a coesão dos traçados que possibilitaram a ação à distância". São os recursos espalhados por essas redes que mantêm apertados os nós da rede por onde transita o conhecimento acumulado. É o trabalho de pesquisa e de produção de inscrições que possibilita esta ação à distância que mantém juntos os aliados envolvidos numa controvérsia. Este é o princípio que inspira a sétima regra metodológica.

As regras metodológicas propostas por Latour (LATOUR; WOOLGAR, 1997, p. 421-422) serão um norte na abordagem de um campo de estudo dificilmente previsível, raramente estático e, em alguns casos, ontologicamente mutável. São estas regras que possibilitam flexibilizar a nossa postura enquanto pesquisadores, assumindo que o mundo é muito mais desordenado do que imaginamos, quando temos a pretensão de fazer da metodologia uma prescrição de higiene (LAW, 2003).

Regra 1: "Estudar a ciência/tecnologia em ação e não a ciência ou a tecnologia pronta. Ou chegamos antes que fatos e máquinas se tenham transformado em caixas-pretas (CP), ou acompanhamos as controvérsias que as re-abrem. Devemos, nesse seguimento, superar duas limitações: a da organização por disciplina e a da organização por objeto".

Essa regra nos leva a perguntar sobre o que fazer com as caixas-pretas da psicologia. Podemos pegá-las, usá-las e fortalecê-las. Podemos rejeitá-las e assim re-abrir controvérsias. Ou podemos transformá-las de tal modo que as deixaremos irreconhecíveis. Para tanto, a psicologia pode abrir um campo inesgotável de estudos, agregando outros aliados, expandindo suas fronteiras e seus campos de pesquisa. A ação de pesquisar não estará encerrada numa perspectiva disciplinar, pois as conexões das redes que sustentam um determinado objeto de estudo poderão ser imprevistas e díspares. O seguimento da ação de um objeto como a pipa, por exemplo, estará sujeito a transpor as barreiras que artificialmente se traçaram entre as várias histórias: da tecnociência, da religião, da infância, do brinquedo, do comércio, do folclore, da aviação, das guerras...

Regra 2: "Não procurar qualidades intrínsecas, mas as transformações que um fato ou afirmação sofre nas mãos de outros". Não podemos mais entender como efeitos desta regra metodológica para a psicologia, como qualidades intrínsecas de uma entidade o seu modo de estar no mundo, de agir e de relacionar-se, a sua cognição e a sua forma de emocionar-se. Será preciso examinar os muitos modos como estas "qualidades" emergem após o estudo da rede que lhes dá sustentação. Só então poderemos trabalhar com a idéia de que algo foge à descrição das redes. Nem pessoas, nem objetos - para pensar simetricamente - possuem qualidades intrínsecas, mas são o resultado provisório de estabilizações que as redes lhes possibilitaram, por meio das conexões que performaram. A pipa não é 
um objeto em si, mas o que fizeram dela nas suas várias traduções, sempre numa tensão de algo que se mantém e de algo que vai se modificando.

Regra 3: "Não poderemos utilizar um efeito ou uma conseqüência como causa para a solução da controvérsia". Nas diversas caixas-pretas fabricadas pela psicologia, é comum fazermos um movimento pendular entre o que é provocado por uma natureza básica e inerente ao nosso aparato biológico e as explicações que fazem recair todo o peso num social dado previamente. Por esta regra metodológica, não podemos tomar a natureza para explicar como são os indivíduos, pois ela é apenas um elemento entre vários, na rede que os constitui. A própria natureza já é uma estabilização provisória em um campo agonístico. Igualmente serão pessoas e objetos numa rede que mescla muitos outros elementos, inclusive a natureza.

Regra 4: "Não podemos usar a sociedade como causa para explicar uma controvérsia. Devemos considerar simetricamente os esforços para alistar humanos e não humanos". 8

Em continuidade com o raciocínio anterior, a sociedade não está previamente dada e não é construída de uma vez e para sempre. Portanto, se levarmos em consideração pessoas e objetos como nós na rede, o social não pode ser considerado como causa a priori das ações na relação que esses elementos estabelecem uns com os outros. Nessa construção em rede, outros elementos - que não só humanos - jogam na constituição das singularidades. Objetos assim como pessoas têm um papel decisivo nesse processo. Para o Princípio de Simetria que orienta a metodologia da TAR, não faz sentido colocar pessoas de um lado e objetos do outro quando realizamos um estudo. A TAR nega que as pessoas sejam necessariamente especiais, principalmente porque se abre a questão sobre o que queremos dizer quando falamos de pessoas (LAW, 1992).

Regra 5: "Como pesquisadores, devemos ser tão indefinidos quanto os vários atores que seguimos. Sempre que houver a diferença interior/exterior, devemos acompanhar os dois lados simultaneamente, incluindo a todos que realizam o trabalho". A indecisão ou indefinição pode ser entendida como uma ausência de pré-julgamentos na tentativa de entendimento dos fenômenos que aparecem como sendo da alçada da psicologia. Se os atores acham que alguma coisa não é consistente, que é controversa ou artificial, nós também o devemos fazer, inclusive com relação a controvérsias históricas já resolvidas. É esta postura que garante a possibilidade do estranhamento do rotineiro e a emergência de um objeto novo. As teorias fabricadas pela psicologia podem ser caixas-pretas, mas estarão sempre passíveis de serem re-abertas. Acrescente-se que a derrubada da dicotomia interior/exterior pela metodologia da TAR também resulta em conseqüências vitais para a psicologia. O que é exterior ao sujeito que não encontre uma tradução em sua maneira de ocupar um nó na rede? O que é interior ao indivíduo que não tenha uma expressão/tradução nas relações que estabelece na rede?

Regra 6: "Diante da acusação de irracionalidade, não olhamos para qual regra lógica foi infringida, nem que estrutura social poderia explicar a distorção, mas sim para o ângulo e a direção do deslocamento do observador, bem como para a extensão da rede que assim está sendo construída. Não devemos tomar posição a 
respeito da ir/racionalidade, mas considerar o movimento do observador em relação ao observado". Esta regra produz a derrocada da postura assimétrica que a psicologia tem tomado ao longo de toda a sua história com relação ao desvio ${ }^{9}$ e à diferença. O que é visto como transtorno/doença passa a ter outra abordagem sob a ótica das redes, pois, em vez de decretar o que é lógico ou ilógico, gerando uma postura de segregação e patologização, passaremos a verificar a sócio-lógica das associações: a) como são feitas as atribuições de causas e efeitos; b) que pontos estão interligados; c) que dimensões e que força têm essas ligações; d) quem são seus porta-vozes; e) como os elementos são modificados durante a controvérsia (LATOUR; WOOLGAR, 2000, p. 331). Tanto os pesquisadores como os objetos que emergem das redes que estudam estarão passíveis de modificações durante a controvérsia, abrindo-se a possibilidade de questionar os a priori de todos os lados. Poderemos considerar como controvérsia no campo da psicologia os vários tipos de ação do psicólogo em cada caso - um processo diagnóstico, um processo terapêutico - enfim todas as oportunidades que oferecem a chance da abertura de caixas-pretas. ${ }^{10}$ A "saúde" ou a "doença" mental, condições absolutamente discutíveis, como objeto da psicologia, perderiam a sua força em prol do estudo das redes que dão sustentação à pluralidade dos casos, ou à variedade de outras temáticas que se nutrem de áreas do conhecimento para além das fronteiras disciplinares. É desta forma que, por esta regra, a psicologia não poderia mais estar na posição de julgar o que é lógico ou ilógico, mas assumiria o compromisso de mudar o ângulo e a direção do olhar do pesquisador para descrever um fenômeno em questão.

O que o fenômeno pipa pode oferecer para as controvérsias instaladas no campo da psicologia? Até o momento, encarada como um fenômeno marginal, campeã nas estatísticas de acidentes variados, ${ }^{11}$ a pipa pode nos ajudar a entender uma série de questões relacionadas às aprendizagens - das destrezas, da ocupação do espaço, das regras que regulam as interações, do controle das emoções, da arregimentação de aliados humanos e não humanos, da percepção das condições climáticas e dos ciclos da natureza, da construção de uma postura ecológica. ${ }^{12}$

Regra 7: "O trabalho intelectual não deve ser separado da rede em que se insere. Teorias ou abstrações não estão separadas das coisas de que falam, o que significa estar sempre viajando pelas redes ao longo de sua maior extensão. A informação é ter alguma coisa sem ter a coisa em si, é o meio-termo entre a presença e a ausência. Antes de atribuir qualquer qualidade especial à mente ou ao método das pessoas, devemos examinar os modos como as inscrições são coligidas, combinadas, interligadas e desenvolvidas". As teorias psicológicas, como quaisquer outras, não podem sobreviver fora da rede que lhes deu origem. Portanto, quanto mais vascularizada for uma teoria psicológica, maior a sua chance de sustentação, sendo maior $\mathrm{o}$ alcance de seus efeitos. Este fato implicaria um constante colocar-se à prova no campo agonístico, assumindo a provisoriedade do conhecimento até que ele se transforme em caixa-preta, ou seja, até que se torne consensual e, portanto, objetivo. ${ }^{13}$ Nesse processo, seria imperioso não utilizar o conhecimento acumulado como arma de rotulação/manipulação dos casos em controvérsia. Generalizando radicalmente o Princípio de Simetria neste campo, nenhuma teoria psicológica com pretensões a universalizar modelos de homem e concepções de saúde e doença poderia 
sobrepujar ou obscurecer o caso particular que se encontra à nossa frente. Cada caso, por sua vez, seria passível da mesma regra metodológica, ou seja, não poderia ser estudado como uma abstração em separado da rede que the possibilitou a emergência. Fato e contexto são inseparáveis. No caso de um fenômeno considerado "desvio", o contexto é o mesmo daquele que constrói a idéia de "norma", sendo coadjuvante na sua emergência, assim como é decisivo na promoção de sua censura.

\section{Para Um estudo ATOR-REDe}

Segundo Law (1997), a descrição de um caso particular pode ser um estudo ator-rede exemplar. Uma das características da tradução é que ela pode ser local e global ao mesmo tempo, pois pode ser "lida" por meio de vários casos particulares. Por esta razão, as narrativas assumem um papel preponderante nos estudos ator-rede, podendo ser feitas a partir dos fragmentos. Destas considerações, o autor destaca algumas propriedades da TAR:

Os casos examinados pela TAR não podem ser contados em uma única narrativa, pois não há uma história que possa capturar todos os aspectos da realidade, nem há uma condição de neutralidade ou independência por parte de quem narra. Uma grande, única e definitiva história nega e exclui outras possibilidades de narrar os fatos, sem levar em conta que o narrador é refém de seu tempo, de sua história e de seus interesses. Há sempre várias formas de narrar um mesmo caso, dependendo de que ponto da rede tomamos para "ler" o caso em questão, de que elementos privilegiamos para tecer a nossa narrativa. Para sermos legítimos, é preciso assumir que, de algum lugar que será sempre uma escolha particular, estamos nos propondo a contar uma multiplicidade de histórias.

A TAR não pode ser tomada de forma centralizada, pois a pressão se faz tanto para unir como para separar coisas. A centralização consumada pode motivar a descentralização e, inversamente, descentralizar pode ser um movimento necessário para chegar-se a um centro. $\mathrm{O}$ aparente confronto entre a centralização e a descentralização, entre unidade e diáspora, entre estabilidade e instabilidade, entre singularidade e multiplicidade aparece como uma marca da tensão em que trabalham as redes.

A TAR pode ser conhecida por meio de um conjunto de pequenas histórias de como os elementos que estabelecem conexões se reúnem momentaneamente por ambivalências e por oscilações. A ramificação das relações, as lacunas e as incompletudes fazem parte da descrição de como os fenômenos se articulam performando uma rede. A preocupação com a consistência foi deslocada na TAR porque a ordenação é um processo provisório e uma vez que as coisas podem estar ordenadas diferentemente em outro instante. Segundo Cukierman (2000), a coerência é meramente contingencial, nunca uma essência, aparecendo como efeito de um quadro que se estabilizou por um momento.

A TAR pode ser conhecida como uma arte de descrever texturas que formam um padrão, um remendo intelectual, como diz Law (1997). A TAR descreve de que forma as várias histórias funcionam como pedaços que podem se ligar numa colcha de retalhos por similaridade e por diferença. Entre as muitas peque- 
nas histórias, podem subsistir padrões que não precisam se reduzir à cronologia da narrativa, pois é possível estarem fora da colcha. Pode ser também que não exista um padrão único e coerente, que cada história sobre práticas locais e específicas baste a si mesma. Quer-se evitar qualquer gênero de narrativa cuja pretensão é uma globalização. Uma conclusão é vista como um fechamento de possibilidades, idéia completamente avessa à proposta das redes e das narrativas plurais.

A TAR está no campo dos experimentos, das tentativas, das invenções e suas narrativas alternativas versam sobre as estratégias da produção de objetos e sujeitos. De acordo com Latour (1996), a melhor forma de explicar é explicitar as conexões entre os elementos em uma rede ou mostrar como um elemento contém muitos outros. Ao colocar várias histórias, uma ao lado da outra, e ao tecer as costuras entre elas, podemos fazer emergir a diferença pela criação de novas relações, escapando da ditadura do já estabelecido. A partir de Latour (LATOUR; WOOLGAR, 2000), podemos entender que, quando produzimos conexões, podemos produzir coerências onde elas não estão dadas. Fabricar um fato é produzir provas, coisas para serem vistas, observadas, comparadas, confrontadas. É isto que fazem os laboratórios, quando funcionam como centros de tradução e de produção de fatos.

A metodologia da TAR, então, consiste basicamente em mobilizar a realidade, ${ }^{14}$ seguindo os atores na rede, e em examinar as inscrições, ou seja, investigar textos, imagens e dados. Os elementos coletados pelos pesquisadores em qualquer campo de pesquisa precisam ser transportados para se tornarem visíveis "sinopticamente", para que possamos operar com eles e para que se constituam em "móveis imutáveis".

O seguimento dos atores em suas redes pode se dar por uma série de procedimentos que variam desde os experimentos de laboratório, às expedições de campo para coleta de material, às entrevistas, aos questionários, ${ }^{15}$ à pesquisa etnográfica, para falar dos já consagrados métodos utilizados. Segundo Latour (LATOUR; WOOLGAR, 2004), não há uma divisão entre as ciências da natureza e as ciências humanas, sendo este seguimento dos atores nas redes válido para as "humanas ciências".

\section{As aStúCIAS do PESQUISAdOR}

Escrever textos, para Latour (LATOUR, WOOLGAR, 2003), tem tudo a ver com o método da TAR, pois esta atividade funciona em modo semelhante àquela que é desenvolvida em um laboratório, lugar em que experimentamos múltiplas combinações para verificar seu efeito. Como qualquer híbrido, a entidade autor-texto troca propriedades - o autor fazendo o texto e o texto fazendo o autor - para produzir algo que não estava necessariamente previsto em seu início, única maneira de entender a produção do novo. Torna-se fundamental o exame das inscrições, pois elas tornam possível o transporte daquilo que se mobilizou na realidade, uma vez que podem viajar através do tempo e do espaço, possibilitando uma comparação com outros trabalhos pelas similaridades e diferenças traçadas. Entre as inscrições, podemos ter os dados, as imagens e os 
textos. Estes últimos oferecem credibilidade ao que é exposto, estabelecem equivalências entre problemas e carregam o trabalho para outras pessoas e instituições. (LATOUR, 1985; LATOUR; WOOLGAR, 2000). Sem as inscrições, os fenômenos só poderiam ser conhecidos pelo imediatismo dos sentidos. São elas que permitem que os fenômenos passem a ser reconhecidos, mensurados e vistos em perspectiva.

De acordo com Latour (1985), é graças à perspectiva que os objetos podem ser percebidos com coerência óptica, mesmo passando de uma condição tridimensional para uma condição bidimensional, quando são transportados por meio de imagens. Essa invenção gráfica e geométrica faz com que as imagens possam fazer tantas viagens de ida e volta, do local ao global, mantendo-se estáveis em suas formas. É o que garante acelerar a mobilidade das imagens, manter a sua imutabilidade e ampliar as possibilidades de re-combinação. Quando representamos em perspectiva os objetos do mundo, assim como os objetos vindos da ficção ou da crença (projetos, utopias, mitologias, imagens religiosas), eles ganham em coerência óptica e em poder de convencimento, como se fossem reais. Por isso, as inscrições de todos os tipos (textos e imagens) são importantes para os pesquisadores porque, tanto mais nítidas, combináveis, re-desenháveis e passíveis de superposição, tanto mais elas oferecem a vantagem de uma prova: um argumento que pode fazer diferença numa discussão.

Para resumir a metodologia que norteia o trabalho de todo o pesquisador, Latour (1985) identifica sete práticas de tradução:

Mobilização que implica o transporte de quaisquer estados do mundo para algum lugar onde são reunidos e trabalhados por comparação ou confrontação com outros trabalhos.

Fixação das formas para que o material sofra o mínimo de deformação possível durante o transporte, possibilitando o seu reconhecimento apesar do deslocamento.

Achatamento pela passagem da condição tridimensional para a bidimensional, ou seja, para que fiquem visíveis numa folha de papel em que podemos dominá-las.

Variação da escala para podermos dominar o infinitamente grande e o infinitamente pequeno. Uma galáxia ou um genoma só se tornam visíveis e trabalháveis quando adaptamos suas escalas às imagens que examinamos. As latitudes e longitudes, os anos-luz, tempos e distâncias se tornam domináveis e compreensíveis porque fazemos variações em suas escalas, adaptando-as ao possível de ser capturado pelo olhar.

Recombinação e sobreposição de traços para promover efeitos visuais que fazem emergir o que costumamos chamar de estruturas, padrões, leis. A impressão de criarmos esses padrões vem da possibilidade de podermos jogar com as inscrições como se elas fossem um jogo de cartas, criando relações onde não esperávamos encontrar. 
Escritura de um texto que incorpore o relato das etapas anteriores. As inscrições transportadas, fixadas, reunidas, achatadas, reduzidas ou ampliadas e finalmente recombinadas resultam na literatura científica.

Fusão com as matemáticas para que as imagens se tornem formas geométricas, diagramas, cifras, colunas, equações. As inscrições podem ser primárias, secundárias, terciárias nestes últimos termos, pelo processo de matematização, para que componham os centros de cálculos.

Essas sete astúcias, tal como as chama Latour (1985), não devem ser isoladas umas das outras. É em seu conjunto que caracterizam o trabalho do pesquisador, acrescentando mobilidade, fidelidade e combinação aos dados com os quais lida. Todos estes passos são tentativas empreendidas pelo pesquisador/cientista para tornar a realidade estável, por meio da fabricação de totalizações parciais, uma vez que nada é dado - nem natureza, nem sociedade - ou construído de uma vez e para sempre.

\section{SEguindo A PIPA}

Neste trabalho, pretendemos lançar mão da metodologia da TAR para seguir a pipa em seus movimentos, nas redes que foi/vai estabelecendo para manterse em ação, pelo exame dos papéis que assume e das metáforas que encarna: como disparador de aprendizagens, como tela de projeções antropomórficas, como instrumento sociotécnico que ensejou descobertas científicas, como inspiradora de inscrições (imagens e textos).

Trata-se aqui de realizar uma fabricação, trabalhando por meio da reunião de materiais variados que, uma vez reunidos, nos servirão para compor um tecido urdido por narrativas que, em sua multiplicidade, possam capturar os movimentos do objeto que está sendo seguido, assim como os seus efeitos. Estivemos debruçados sobre as inscrições que nos permitiram conhecer a pipa em sua história, sobre aquilo que ficou plasmado nos livros e nos deu acesso a uma quantidade de informações que nos chegaram atravessando tempos e espaços. Estivemos seguindo a pipa, em sua ação, pela observação que dela fizemos nos vários eventos em que foi um catalizador de associações, fosse no Festival de Papagaios promovido pela CEMIG em Belo Horizonte, fosse na Oficina de Pipas realizada pela Brinquedoteca da UFSJ, fosse em nossas esparsas observações da brincadeira, que acontecia nas esquinas e arredores dos lugares por onde lançamos o olhar durante a temporada ${ }^{16}$ em que os ventos lhes eram propícios. Visitamos e ouvimos as pessoas responsáveis pela promoção, nestes últimos 24 anos, dos Festivais de Papagaios, que fizeram a opção de respeitar a alta vinculação deste brinquedo/brincadeira tradicional, utilizando-o como aliado nas campanhas pedagógicas sobre o uso da eletricidade e dos recursos ambientais, em vez de tê-lo como oponente a ser extinto. Também ouvimos e registramos algumas histórias de pessoas que tiveram a pipa como objeto de alta significância na composição de suas biografias. Na maior parte das vezes, estas eram pessoas com idades que variavam entre 30 e 70 anos. Nestas narrativas, estiveram sempre presentes ingredientes, tais como: os aspectos da paixão quase religiosa pelo objeto, os aspectos da aprendizagem e da sua transmissão, os aspectos de engenho e arte emergentes da tarefa de sua construção. 
Recolher e acolher a multiplicidade de narrativas sobre a pipa é uma parte de nossa estratégia metodológica, mediante entrevistas ${ }^{17} \mathrm{com}$ pessoas que têm a pipa como objeto privilegiado em sua biografia. A partir dessa coleta, tentaremos verificar como a pipa se situa nas traduções deflagradas pelas diferentes associações estabelecidas em sua versão local. O local, na TAR, é uma parte do global, ${ }^{18}$ ambos versões que, em momento nenhum, podemos entender como opostas. Tentamos, sempre que possível, trabalhar nesta tensão que o modelo das redes nos oferece: centralizando - pelo exame do que parece ser regular e semelhante na comparação com outras práticas ${ }^{19}$ - e, descentralizando, naquilo que a pipa oferece como singular, nas práticas locais.

A temporada de pipas constitui-se em campo fértil para a observação ${ }^{20}$ de como se dão as relações entre aqueles que brincam com o seu objeto lúdico, assim como com os outros incluídos na brincadeira, seja como colaboradores ou como opositores nas chamadas "guerras no ar". ${ }^{21}$ As aprendizagens realizadas neste contexto informal da brincadeira de rua são outro item a ser observado: desde a construção da pipa até a sua colocação no ar, há uma quantidade de mediações ${ }^{22}$ que nos proporcionam um espaço de reflexão sobre a questão da aprendizagem de um corpo que se afeta, que se mobiliza no contato e no manejo com os materiais, com os outros humanos e com as emoções suscitadas nestas relações. $\mathrm{O}$ acompanhamento e registro sistemático desses eventos é uma das nossas estratégias metodológicas para produzir inscrições. Para produzir essas inscrições, pretendemos utilizar instrumentos tais como o tradicional diário de campo, além de máquina fotográfica digital e eventualmente um gravador. Esses instrumentos compõem um arsenal de objetos que têm a ação de "aumentar a mobilidade, a estabilidade ou a permutabilidade dos elementos" (LATOUR; WOOLGAR, 2000, p. 370) e que, portanto, serão bem-vindos por acelerarem um ciclo de acumulação. ${ }^{23}$

Entendemos que as inscrições levantadas, por meio das narrativas ${ }^{24}$ dos brincantes, do registro das observações da brincadeira durante a temporada de pipas, assim como das imagens ${ }^{25}$ colhidas durante os eventos, irão nos proporcionar material para tecermos a colcha que fará emergir os padrões e texturas de um quadro que teremos a pretensão de apenas olhar em uma estabilização provisória, na forma como os elementos desta rede se articulam. É sobre essa rede local que precisamos saber mais, verificando como ela se atualiza dentro do nosso tempo e espaço de pesquisa.

Temos a intenção de tomar o nosso texto como um laboratório das várias inscrições disponíveis. Buscamos a coerência entre textos e imagens numa mistura experimental para a constituição de um todo que será a nossa fabricação. Às narrativas dos brincantes pretendemos acrescentar imagens das obras de arte, ${ }^{26}$ assim como fragmentos de textos literários ${ }^{27}$ em que a pipa tenha figurado como actante, ${ }^{28}$ uma vez que temos verificado que a pipa é um elemento bastante utilizado na literatura e nas artes. ${ }^{29}$ Há muitos artistas populares que tomam a pipa como inspiradora de obras que versam sobre o lúdico, assim como há muitos escritores e poetas que tiveram a pipa registrada em fragmentos de suas obras: Carlos Drumond de Andrade, Thiago de Melo, Eça de Queiroz, Alexandre Dumas, compositores populares conhecidos e desconhecidos, para citar apenas algumas possibilidades. 
Corroborando o até agora exposto, a postura do pesquisador será a de um tradutor, assim como a de um porta-voz e um fabricador de fatos. Tradutor porque lançará mão das práticas de tradução já mencionadas no transporte da parte da realidade que estará pesquisando. Porta-voz, pois estará na posição de quem fala em lugar de algo ou alguém que não pode ou não sabe falar: será aquele que irradia ou que representa a controvérsia e estará tão mais apto a esta tarefa quanto mais aliados puder arregimentar durante a sua pesquisa. ${ }^{30}$ Fabricador de fatos, pois, por meio da produção de inscrições, alimentará um enorme ciclo de acumulação de conhecimento. Cabe ressaltar que o pesquisador, dentro da postura simétrica postulada pela TAR, não ocupa posição de nenhum privilégio ante os elementos que compõem o campo pesquisado. Ele será mais um nó na rede, interferindo e sofrendo interferências das ações que estiver acompanhando. Desta forma, a prescrição de neutralidade perde o sentido, pois se remete a uma concepção de pesquisa engendrada à luz do pensamento moderno a partir de uma divisão purificadora entre saber científico e saber do senso comum. O pesquisador estará inteiro - com toda a sua bagagem de vida - e vinculado/misturado ao seu campo de pesquisa: ele também faz parte do campo.

A questão da autoria assume, na TAR, um novo viés, ou melhor, uma outra tradução. Já que "quem conta um conto aumenta um ponto" ${ }^{31}$ nossas narrativas serão sempre atravessadas por muitas vozes. Integrar um grupo de pesquisa em torno de determinados temas e autores já seria suficiente para um compartilhamento de orientações que vão se mesclando no trabalho de fabricação de inscrições. As traduções ${ }^{32}$ serão inevitáveis e bem-vindas.

Como para qualquer objeto, não se trata de tarefa simples esse seguimento da pipa, ainda mais se tratando de um objeto voador que, em sua dança ontológica, ${ }^{33}$ assumiu diversos papéis ao longo da história, sempre se metamorfoseando e pulando de uma rede à outra. A pipa aparece como um objeto cuja ontologia é sustentada por redes variadas e requer ser estudado nos efeitos que produz em determinados grupos. Torna-se importante, para nós, dentro da metodologia da TAR, descrever as cadeias que promovem tais efeitos, pois se trata de um objeto que não se esgota em si mesmo, que tem vínculos nas práticas que associam humanos e não humanos, abrindo-se a muitas possibilidades de ação. Como a boneca contadora de histórias de que nos fala Spink (2003), a pipa é ao mesmo tempo uma história social e um artefato, um híbrido de socialidade e materialidade.

Entendemos que o trabalho de seguir a pipa em ação requer o movimento de soltar-se ao sabor do vento, mas, ao mesmo tempo, a necessidade de ter uma linha que nos ligue ao chão, sem o que a pipa não voa. ${ }^{34}$ Para nós esta é uma boa imagem de um trabalho de pesquisa: voar tão alto quanto pudermos, porém sem perder a nossa ligação com o solo. Pretendemos que essa ligação seja a metodologia da TAR, suficientemente flexível para nos dar a liberdade de voar, ao mesmo tempo em que nos impele a buscar coerência nas empreitadas para realizar uma boa fabricação. Da mesma forma que os humanos, os objetos também têm uma história a ser contada, são nós de uma rede bem ou mal vinculada, produzindo bons ou maus efeitos. Descrever estes vínculos e aquilo que eles movem nos possibilita ir além dos objetos, pela verificação de como as trocas de propriedades 
entre humanos e não humanos modificam a ambos e operam modificações na realidade. Contar a história dos objetos é resgatar a nossa própria humanidade.

"Pois se não somos mais capazes de reunir coisas para contar grandes histórias sobre o crescimento ou declínio das redes, então o que há para contar?" (LAW, 1997, p. 13).

\section{Notas}

1 De acordo com Latour (LATOUR; WOOLGAR, 1997, p. 288), inspirado em Serres, esta relação ordem/desordem é bastante familiar aos biólogos, segundo os quais a própria vida é resultado da bricolagem, do acaso, da mutação e da desordem.

2 Uma inscrição é uma operação material de criação de ordem em que se produz um híbrido que diz alguma coisa, que oferece informações (imagens, gráficos, textos), usadas como camada final em um texto científico (LATOUR, 1985; LATOUR; WOOLGAR, 1997, 2000).

3 Os centros de acumulação são locais onde: (a) acumulam-se inscrições para que tudo se torne familiar, finito, próximo e útil; (b) faz-se o trabalho de intensificar uma das três características das inscrições: mobilidade, estabilidade, permutabilidade. É desta forma que o conhecimento transita, indo e voltando dos centros de acumulação, numa rede de materiais muito heterogêneos, com o objetivo de atuar à distância (LATOUR; WOOLGAR, 1997, 2000).

4 Este é o processo de criação dos "móveis imutáveis", composto pelas sete astúcias do pesquisador (LATOUR, 1985; LATOUR, WOOLGAR, 2000, 2003), como veremos mais adiante.

${ }_{5}$ Temos uma caixa-preta quando um fato ou um artefato é dado como pronto, adquirindo uma estabilidade provisória na medida em que cessam as controvérsias ao seu redor. Diz-se então que fechamos a caixa e ela assim permanecerá enquanto fato e artefato funcionarem bem. Se alguma coisa deixa de funcionar ou se algo ou alguém ficou excluído, voltamos às controvérsias e reabrimos a caixa (LATOUR; WOOLGAR, 2000).

6 A pesquisa, como qualquer outro campo agonístico em que há forças se digladiando, tem a ação do pesquisador orientada para um "campo" que não se confunde com um território, mas toma a forma de uma rede por onde o pesquisador deve viajar. Colocamo-nos à prova como representantes daquilo em nome de que falamos, ou seja, da controvérsia que testemunhamos. A controvérsia será ganha se conseguirmos reunir num ponto o maior número de aliados.

7 Que, uma vez feita, também pode ser desfeita, bastando que as associações que compõem essa rede se enfraqueçam.

8 Os não humanos compõem os coletivos com os humanos, tendo a potencialidade de exercerem ou sofrerem algum tipo de ação, participando de um processo. É tudo que, não sendo humano, joga a favor da construção da nossa humanidade.

9 Os modernos, na sua ânsia de purificação, tomaram o desvio e o erro como algo a ser evitado, operando-se sobre ele um movimento de censura e patologização. Moraes $(2000,2004)$ desenvolve, com base nas idéias de Canguilhem, uma interessante argumentação sobre o normal e o patológico que pode fermentar esta discussão.

${ }^{10}$ No campo da psicologia, poderemos encontrar como caixas-pretas: 1) conceitos estabelecidos consensualmente, pois se tornaram, em determinado momento no campo agonístico, mais fortes que outros tantos conceitos equiprováveis, mas que precisam ser revistos, pois alijaram ou deixaram de fora um grande número de pessoas, como é o caso das teorias do desenvolvimento ou das teorizações sobre a norma e o desvio; 2) casos de pessoas que estão em sofrimento, pois se sentem desconfortáveis em sua forma de estar no mundo: tal como acontece com as máquinas, algo para estas pessoas "não funciona" e elas buscam ajuda no desejo de desatar os nós da rede que dá sustentação a esse estado de coisas, em prol de uma outra tessitura que lhes permita uma maior capacidade de vinculação (dentro da idéia de tornar-se cada vez mais vinculado e, portanto, cada vez mais diferenciado).

${ }^{11}$ Houve períodos em que a pipa foi apontada como campeã nos acidentes com a rede elétrica registrados pela CEMIG, implicando várias ações didáticas em prol da prática de um esporte seguro. Hoje, esta situação está mais amenizada, mas não faltam casos de motoqueiros que são feridos pelo cerol afiado das linhas utilizadas para soltar pipas. 
${ }^{12}$ No Festival do Papagaio que ocorre em Belo Horizonte há 24 anos, a CEMIG procura desenvolver esta consciência ecológica, ligando o evento a uma postura de preservação ambiental.

13 Segundo Latour (LATOUR; WOOLGAR, 2000), "subjetivo" é a qualidade atribuída ao enunciado de quem fala em seu próprio nome, podendo não enunciar mais do que sonhos ou devaneios. "Objetivo" é a qualidade atribuída ao enunciado de quem fala em nome de muitos uma vez que a construção de um fato é um processo absolutamente coletivo.

${ }^{14}$ Mobilizar a realidade é, para Latour (LATOUR; WOOLGAR, 2001), o trabalho de construir móveis imutáveis, tal como foi feito com a floresta amazônica, em experiência narrada neste livro. Trata-se de um dos nós que compõem a rede que dá sustentação ao fato científico.

${ }^{15}$ Uma solução para os questionários, segundo Latour (LATOUR; WOOLGAR, 2000, p. 380), é fazer com eles "aquilo que fizeram com as pessoas, ou seja, extrair deles alguns elementos e colocá-los em outro formulário mais imóvel e mais combinável". Entendemos que a mesma lógica se aplica a outros instrumentos para mobilizar e transportar a realidade numa cadeia de inscricões que possam ser manuseadas, traduzidas, confrontadas e combinadas.

${ }^{16}$ Pelo fato de não ocorrer durante a época das chuvas e ser mais facilmente colocada no ar durante a temporada dos ventos, a pipa é uma brincadeira sazonal. No caso de São João del Rei, ocorre no período compreendido pelos meses de junho, julho (que coincide com o mês das férias) e agosto. Não havendo chuvas durante os meses de verão, elas também aparecem nas férias de janeiro e/ou fevereiro.

${ }^{17}$ Entendemos que as entrevistas aqui funcionam como um convite às pessoas para contar histórias, para atribuir sentido ao objeto em questão, dentro das atividades da vida. Não pretendemos estabelecer uma quantidade pré-determinada de narradores para entrevistar. Nem temos a intenção de enquadrar os narradores em faixas etárias. Dentro de um Princípio de Simetria Generalizada, as falas de narradores de 8 a 80 anos - para exemplificar uma faixa - seriam igualmente importantes para entender o fenômeno Pipa. A única condição para ser narrador seria o envolvimento com o brinquedo.

${ }^{18} \mathrm{O}$ que aqui chamamos de global é aquilo que é recorrente em vários lugares, que assume o caráter de uma suposta "universalidade" por aparecer com regularidade em muitas versões, mundo afora.

${ }^{19}$ Como exemplo de regularidade nas ações empreendidas pela pipa, temos as práticas de pesca detectadas por Leroi-Gouham nos arquipélagos da Malásia e encontradas em versão semelhante no litoral de Santa Catarina, sem que tenha sido verificada qualquer comunicação entre as pessoas que tiram partido deste tipo de estratégia.

${ }^{20}$ A pesquisa de campo foi prevista em função da sazonalidade da brincadeira, nos anos de 2005 e 2006.

${ }^{21}$ Esta é a expressão utilizada no estudo dos papagaios de Belém, realizado por Pontes et al. (2003), para designar as disputas inerentes à brincadeira com a pipa, brinquedo que assume características específicas em termos dos comportamentos que deflagra e dos vocabulários que mobiliza em cada lugar, fato que se torna um indicador das tradições locais, apontando onde estas se conectam com o mesmo tipo de atividade desenvolvida em outros lugares.

${ }^{22}$ Mediação, entendida aqui como aquilo que está no meio e que interfere, refere-se aos efeitos provocados tanto por humanos como aqueles deflagrados por não humanos.

${ }^{23}$ Um ciclo de acumulação é o processo pelo qual passa a realidade quando é mobilizada, transportada, reunida, arquivada, codificada por meio da pesquisa, resultando em conhecimento acumulado que age à distância por meio de grandes redes.

${ }^{24}$ Pretendemos utilizar o gravador para registrar e transportar essas narrativas.

${ }^{25}$ Pretendemos registrá-las por meio do recurso das fotos digitais, colhidas durante o seguimento dos eventos em que a pipa figurar como protagonista.

${ }^{26}$ Em Latour (1985), encontramos o comentário sobre como as obras de arte - pintura, escultura são porta-vozes de como uma cultura vê o mundo e/ou de como o torna visível. Segundo o autor, "visões de mundo" é uma metáfora que deve ser tomada literalmente, pois redefine o que se viu e o que há para ver. Trata-se de uma maneira de pôr o mundo em cena que encontra traduções na arte, na ciência, na economia, na religião.

${ }^{27} \mathrm{Na}$ perspectiva de uma antropologia simétrica, tentamos amenizar as barreiras que separam o texto acadêmico do texto literário, buscando contar "uma boa história", tornando-a "psicologicamente relevante", para seguir a sugestão de Spink (2003).

${ }^{28}$ Actante, palavra originária da semiótica, designa, segundo Latour (LATOUR; WOOLGAR, 2001), todo aquele elemento, humano ou não humano, que produz ou sofre modificações em ações praticadas.

Revista do Departamento de Psicologia - UFF, v. 19 - n. 1, p. 169-186, Jan./Jun. 2007 
${ }^{29}$ Mello (1983) nos dá notícias de como as pipas, como elementos plásticos e dotados de grande harmonia na relação forma e espaço, têm inspirado pintores contemporâneos de diversos países e estilos. Segundo o autor, podemos encontrar a pipa em quadros de Portinari, Guignard e de Di Cavalcante, obras que pretendemos verificar.

${ }^{30}$ Sobre esse assunto, ver Latour (1983) que narra como Pasteur com seu laboratório "descobriu" a ação dos micróbios e deu ensejo a uma série de mudanças que afetariam drasticamente as concepções sobre saúde e doença da época.

${ }^{31}$ Ditado popular que captura bem o movimento de "traição" que se opera nas cadeias de tradução, quando a informação vai passando de boca em boca dentro da tradição da oralidade.

${ }^{32}$ Que, segundo Law (1997), vão suscitar traições, no sentido de que vão acrescentar algo à cadeia, marcando diferenças em relação ao que era no início.

${ }^{33}$ Segundo Law (1997), existe uma natureza dançante na ontologia das entidades, pois sua identidade e suas propriedades nunca são dadas definitivamente, sendo a sua ordenação o resultado provisório das conexões que estabelecem em determinadas redes. Uma "coreografia ontológica" encerra essa possibilidade de os elementos desempenharem diferentes papéis em uma rede.

${ }^{34}$ Em Minas, chamamos de "pipa voada ou avoada" aquela que teve a linha cortada e perde a direção. Nesse caso, não tem dono e passa a ser disputada por todos até ser capturada por alguém. É provável que essa denominação também seja usada em outros lugares.

\section{REFERÊNCIAS}

CUKIERMAN, H.L. Eudóxia: uma viagem pela multiplicidade. Arquivos Brasileiros de Psicologia, Rio de Janeiro, v. 52, n. 3, p. 15-27, jul./set. 2000.

LATOUR, B. Dê-me um laboratório e eu erguerei o mundo. Traduzido do original: Give me a laboratory and I'll arise the world. In: MULKAY, M.; KNORR, K. (Ed.). Science Observed Sage. [S.1.: s.n.], 1983. p. 141-170.

. As visões do Espírito: uma introdução à antropologia das ciências e das técnicas. Culture et Technique, [S.1.], n. 14, p. 5-29, 1985. Traduzido para Publicações didáticas. Março, 1990 por J.M.Carvalho de Mello e C.J. Saldanha Machado.

. On actor-network theory: a few clarifications. Soziale Welt, [S.1.], v. 47, n. 4, p. 369-381, 1996.

LATOUR, B.; WOOLGAR, S. A vida de laboratório: a produção dos fatos científicos. Rio de Janeiro: Relume Dumará. 1997.

Ciência em ação: como seguir cientistas e engenheiros sociedade afora. São Paulo: UNESP, 2000. . A esperança de Pandora. Bauru, SP: EDUSC, 2001.

. Dialog on Actor Network Theory. [S.1.: s.n.], 2003. Disponível em: < http://www.bruno-latour.fr/articles/article/090.html >. Acesso em: 12 dez. 2004.

Políticas da Natureza: como fazer ciência na democracia. Bauru, SP:

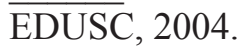

LAW, J. Notas sobre a teoria ator-rede: ordenamento, estratégia e heterogeneidade. 1992. Disponível em: <http://www.lancs.ac.uk/fss/sociology/papers/law-notes-onant.pdf>. Acesso em: 12 set. 2004. 
Tradução/Traição: notas sobre a Teoria Ator-Rede. [S.1.: s.n.], 1997. Disponível em: <http://www.lancs.ac.uk/fss/sociology/papers/law-traductiontrahison.pdf $>$. Acesso em: 2 out. 2004.

. Making a mess with method. 2003. Disponível em: <http:// www.lancs.ac.uk/fss/sociology/papers/law-making-a-mess-with-method.pdf>. Acesso em: 2004.

MELLO, T. Arte e ciência de empinar papagaio. Rio de Janeiro: Civilização Brasileira, 1983.

MORAES, M. O. O conhecimento científico: da epistemologia às redes sociotécnicas. Arquivos Brasileiros de Psicologia, Rio de Janeiro, v. 52, n. 3, p. 76-88, jul./set. 2000.

O que é a psicologia? Revista de Psicologia da UnC, Santa Catarina, v. 1, n. 2, p. 69-73, 2004.

PONTES et al. Guerra no ar: tradição e cultura do papagaio de Belém. In: CARVALHO A. M. et al. (Org.). Brincadeira e cultura: viajando pelo Brasil que brinca. São Paulo: Casa do Psicólogo: EDUSP, 2003. v. 2.

SPINK, P. K.Pesquisa de campo em Psicologia Social: uma perspectiva pósconstrutivista. Psicologia e Sociedade, Porto Alegre, v. 15, n. 2, 2003, p.18-42.

Recebido em: julho/2005

Aceito em: junho/2006 
